Government appointed a working party under the chairmanship of the chief inspector of explosives to investigate the matter experimentally, and a report* has now been issued. The experimental work was carried out mostly by the officers of the chief superintendent of armament research ; but officers of other departments also collaborated.

Ammonium nitrate is liable to cake into a hard mass soon after manufacture; so as to keep it in a free-running condition the American product is mixed with about 1 per cent of a hydrocarbon resembling 'Vaseline' and 5 per cent of kaolin. It is packed in 100-lb. paper bags of six-ply, two of which are coated with an asphaltic composition. On the other hand, the British material for agriculture is a practically pure synthetic product (ammonium nitrate 99.8 per cent; water about 0.15 per cent). It is packed in steel drums containing $4 \mathrm{cwt}$. each.

Laboratory experiments showed that a mixture of the composition of the American product ignites more readily than pure ammonium nitrate. This was confirmed by field trials in which the two products were heated under the same conditions in artillery shells. Not only did the American material decompose more quickly and at a lower temperature than the British, but also it was liable to explode violently, whereas the British product either did not explode at all, or only did so mildly. When heated in steel tubes $2 \mathrm{ft}$. long by $0.45 \mathrm{in}$. in diameter by $0.08 \mathrm{in}$. thick, the British product burst the tube only at the end where it was actually heated, whereas that from America burst it from end to end, showing that explosion had spread to the unheated portion.

Trials on a larger scale were then carried out at the island of Dune in Heligoland Bay with British ammonium nitrate. Seventy tons of it were stacked in drums in an underground bunker of reinforced concrete, and a fire was lit of some fifteen tons of a mixture of wood and ammonium nitrate. There was no explosion, although there was evidence that the interior of the bunker had been raised to a red heat.

Similar trials were carried out in two steel lighters (or barges). In one case the ammonium nitrate was in drums and in the other in bags. In neither case was there an explosion, although the recorded temperature in the space above the nitrate rose to $500^{\circ}$ C., and there was evidence that part of it attained a red heat. Samples of the atmosphere in the bunker and lighters were taken during the fires by an automatic apparatus. Their analysis indicated that much of the ammonium nitrate had been decomposed by the heat into oxygen, nitrogen and oxides of nitrogen.

The trials, therefore, indicate that when pure ammonium nitrate is heated it decomposes, and the pressure developed may burst the container; but even with strong confinement explosion does not extend beyond the material actually heated. Although it cannot be stated with absolute certainty that in a large consignment stored in bulk self-confinement might not lead to a true explosion of the mass in some exceptional circumstances, the results obtained show that British ammonium nitrate under normal conditions of storage and transport is safe.

Admixture of combustible material, such as paper and wood, in pieces of visible size did not cause

- Report on Experimental Investigations on the Safety in Storage and Transport of Ammonium Nitrate. By W. A. Bailey. 12 pp. +11 pp. of appendixes +16 pp. of illustrations. explosion in mass. Therefore safety does not appear to be threatened by the use of paper bags or linings of waxed paper to the steel drums, although the use of such inflammable material is open to criticism.

A small amount, such as 1 per cent, of hydrocarbon mixed intimately with ammonium nitrate alters its behaviour when strongly heated. With strong confinement the decomposition becomes explosive, and the explosion may be propagated throughout the mass. Large-scale experiments were not, however, carried out with this mixture.

ARThur Marshall

\section{0 \\ VALVE PORT DESIGN OF COMPRESSION-IGNITION ENGINES}

ONE limitatiop on the maximum power developed by an internd an woustion engine is the volumetric efficienc, Whech is a function of so many variables that the $r$ interrelation is unfortunately not always und stood. However, in a paper read before the Inst uton of Mechanical Engineers and entitled "Whe Tnfluence of Valve Port Design on the Volunffurid - Ifficiency of the Compression-Ignition Ev ine", Mr. C. B. Dicksee succeeds in explaining clearly how these factors affect volumetric efficiency, and discusses the results of experiments carried out to compare the pressure loss in various forms of venturi and straight-sided inlet ports.

The practical results of the experiments are perhaps unexciting, confirming, as they do, what has long been known and practised. Confirmatory and quantitative evidence is, however, always useful, and one particularly valuable result is that those ports which have the best performance under steady-flow conditions are found also to show the smallest losses at full load over the highest speed range. This, of course, means that the effectiveness of a port may be determined by testing it on a simple blowing rig.

The experiments consist of three series of tests, each with some six different shapes of port, and performed under steady-flow, motoring and full-load conditions. In the first series a marked improvement in the pressure loss when using the venturi is found, provided the valve seat is of adequate diameter. The other series confirm that under practical conditions it is valve-seat diameter, only, that is of importance, passage shape having a negligible effect, since its influence is so small compared with that of other factors which arise under running conditions. Other things being equal, the venturi is preferred, as it provides much-needed space in the cylinder head for the injector.

The greatest interest of the paper lies not so much in the experiments as in the comparison of petrol. engine and Diesel breathing requirements, the description of the induction process in the latter and the clear exposition, helped by some excellent light. spring diagrams, of the various complicating factors which influence volumetric efficiency. It is refreshing to find an expert who does not lay the burden of all unexplained phenomena, which transpire during the exhaust and early induction period, on the shoulders of those convenient scapegoats, exhaust pressure waves. Particularly sound is the explanation of why the motoring volumetric efficiency should be considerably higher than full-load volumetric efficiency 
at low speeds, yet fall off sometimes even below the full-load value (which remains nearly constant) at high speeds. One may perhaps complain that at one point the author is not quite precise in his explanation as to why heat transfer from a cylinder wall to a turbulent charge does not increase pro rata with the scrubbing velocity, and, at another, no definition is given of "conventional velocity", the abscissa of one of the curves; but these are very small details. It is a paper pleasantly written, the reading of which should throw considerable light on the hidden processes of the compression-ignition engine.

$$
181=
$$

\section{TRAINING FOR MANAGEMENT}

$\mathrm{A}$ $\mathrm{T}$ a recent cócerence at Ashorne Hill, Leamington, which was organised by the West Midlands group of thoritish Association for Commercial and Industrial Sducation, the subject of training for managetnd was examined by means of lecture and discassion.

Atloducing the first session, Sir Charles Bartlett, mandging director of Vauxhall Motors, reminded the conference that management was not an end in itself but a vital weapon in a nation's struggle to maintain its existence, a struggle in which failure meant utter disaster. The first speaker, Mr. D. B. Brown, managing director of the Glacier Metal Co., analysed the process of management into three stages. First, the making of policy; secondly, the decision on applying policy; and, thirdly, the execution of policy. The manager, Mr. Brown suggested, was the executive; but in the first two stages he had no more right than the other two main interests concerned, the producer and the consumer. He should see that decisions at these stages were shared with them. Although the consumer could not be consulted directly, his wishes normally were expressed through the working of the market. The producer, the man in the works, can and should be consulted. He must feel that his opinion and individuality were respected. For the third or executive stage the manager must possess real power that comes from acting with consent.

In the discussion Sir Charles Bartlett referred to other elements in responsible leadership, among them the need to lead by example. Speaking of sharing responsibilities, he said that joint consultation was sterile unless there was some real devolution of authority. In his own company, for example, authority to deal with absenteeism had been given to a joint committee and had resulted in an absence figure of less than 1 per cent.

Introducing the second session, Sir Graham Cunningham stated that management training could at least be accelerated by systematic study. 'The theoretical training should include the manager's preliminary education, which might end at fifteen, eighteen or twenty-one years; some training to enable him to grasp the ideas of his time; and the acquisition of knowledge of the processes and the organisation of his particular firm. The speaker in this session, Mr. N. C. Rimmer, considered the shortcomings of many of the existing methods of theoretical training for management and pointed to two things which must be done as part of this training. First, there was the study of responsibilities and functions in the process of getting a job done; secondly, there was the study of how orders should be given, to whom, by whom, and by what method.
The speaker at the third session was Mr. John Ryan, vice-chairman of the Metal Box Co., who quoted twelve attributes which had been postulated as necessary for a business leader: physical and nervous energy; enthusiasm ; alertness ; imagination-including a lively curiosity and interest in new ideas ; character-among other things he must be truthful, temperate, and sincere ; sound judgment ; courage-especially to take decisions which could not please everybody; sense of humour; the ability to listen; a knowledge of human nature, with the ability to see through other people's eyes; and finally a sense of purpose and belief in his job.

Though almost all these qualities could be developed, Mr. Ryan pointed out that some were innate, and careful selection must precede training. The training of potential managers in the works would involve close surveillance by higher management. After training in administrative work the man should be given a job of his own as soon as possible, while training in specific subjects should continue. His training should also include attendance at conferences, both national and international.

In the fourth session the speaker was Prof. T. $H$. Marshall, who read a paper on the "Manager and the Community". In looking at management from the outside, Prof. Marshall stated that it was not always possible to distinguish between direction and management functions; the former, dealing with policy, was more relative to the major issues. This subject was fundamental in dealing with problems of social order, distribution and property, and distinction of class. Considering the actual position of management to-day, Prof. Marshall said that two questions to be answered were whether society regarded management power as legitimate, and what the responsibilities of management were-to whom and through whom.

Turning to the nature of management responsibility, Prof. Marshall traced its four directions : to the owners, or shareholders in the business; to the State, through the Government; to the customer or consumer; and to the worker in industry. If he had to place one of these first, he would choose the consumer; his interests were generally shared by the other three, whose individual interests might conflict. There was no machinery, he pointed out, for resolving such conflicts, no set of rules to be referred to. This situation, however, was common in the older professions-medicine, for example, with the conflicts, of which there were recent examples, between its responsibilities towards its patients, the community and its own science. Such conflicts were solved by building up a code of professional ethics, to which they could be individually referred. In Prof. Marshall's view, management needed a similar professional code of ethics, though it did not need the same rigid system of controlling entry and prescribing qualifica. tions as for the professions.

Summarizing the conference, Mr. Ronald Ogden, general secretary of the British Association for Commercial and Industrial Education, stressed the necessity to realize that, whether managers like it or not, industrial democracy had come to stay, and that they must tackle the problems involved in a realistic manner. Joint consultation was one of the ways of tackling them; but joint consultation if adopted must be introduced sincerely on the part of management, and must not be looked upon as mere 'window dressing'.
T. H. HAWKINS 